\title{
Influence of Thermal Modification on Performance of Plantation Poplar Wood
}

\author{
WANG Yong, CHEN Zejun*, FAN Youhua \\ Institute of Forest Products Industry, Hunan Academy of Forestry, Changsha, Hunan, China
}

Keyword: Thermal treatment, mechanical performance, dimensional stability, ASE

\begin{abstract}
. poplar wood was applied as study object and series of research were carried out in the influence of time and temperature on the performance of heat-treated wood samples. The results showed that the dimensional stability and mechanical properties of heat-treated wood samples were influenced significantly by temperature and time. After comprehensive consideration on treat time, temperature and total modification cost, the optimum condition of temperature and time was chosen as $180{ }^{\circ} \mathrm{C}$ and $3.5 \mathrm{~h}$.
\end{abstract}

\section{INTRODUCTION}

The resource of plantation wood is abundant in China, and under the background of the increasing scarcity of high-quality large-diameter logs resources, the planting scope and area of fast-growing plantation poplar as an important timber species in China have been greatly expanded. At the same time as an important plantation area, poplar acreage and volume of Hunan Province also has a fast-growing in recent years, and thus the development and application of poplar wood get more and more attention from researchers. Poplar wood has wide applications in many fields. However due to fast growth speed and short rotation periods, the poplar wood is soft with low density and it has poor physical and mechanical properties that make the application range severely limited[Chen Zejun, 2008], [B. F. Tjeerdsma, 2005]. Therefore, it is expected to improve properties and expand the application scope of fast-growing plantation wood. At present, most of studies are chemical modification which can effectively improve the performance of fast-growing wood. And to some extent, some of these methods are of great value and extensive application. However, there are still many problems remaining such as high modification cost, low output and not fit for large-scale industrial production, and especially potential damage to both human body and environment[R. G. Martinez, 1996], [J. Ratnasingam, 2011]. Moreover, since most of modified wood are chemically treated and after expiration how to deal with the large number of abandoned chemically modified wood is a hot potato in future.

All of these problems are concerned by researchers. And compared with conventional chemical methods, physical methods are more environment-friendly with lower cost. Especially, thermal treatment technology is one of the most potential physical modification technology at present[Zhang Yamei, 2013], [B. F. Tjeerdsma, 2005].

In this paper, poplar wood was applied as the study object, and hot steam as the modification medium. Modulus of rupture (MOR), modulus of elasticity (MOE) and anti-shrinkage coefficient (ASE) were tested to research the influence on the dimensional stability and physical performance of thermal modified wood samples. From this study, the optimum condition was chosen.

\section{MATERIALS AND METHODS}

\subsection{Materials}

The wood samples were derived from 6-year-old trees in YuanJiang, Hunan Province. One size of samples was $300 \mathrm{~mm}$ in longitude, $20 \mathrm{~mm}$ in radial direction, $20 \mathrm{~mm}$ in tangential direction. The other size was $20 \mathrm{~mm}$ in longitude, $20 \mathrm{~mm}$ in radial direction, $20 \mathrm{~mm}$ in tangential direction 
All samples without visible defects were selected out and divided into several groups and then kept in the conditioning chamber $\left(20{ }^{\circ} \mathrm{C}, 65 \%\right.$ R.H. $)$ until the moisture content reached an equilibrium of around $12 \%$.

\subsection{Methods of thermal treatment}

(1) Preprocessing stage. The samples should be kept in the conditioning chamber for several weeks before treatment until the moisture content reached an equilibrium of around $12 \%$.

(2) Thermal treatment stage. The samples were put in the treatment tank which was then sealed and heated. After the temperature in the tank reached $60{ }^{\circ} \mathrm{C}$, put hot steam into the tank. And when the temperature reached the set values $\left(170{ }^{\circ} \mathrm{C}, 180{ }^{\circ} \mathrm{C}, 190{ }^{\circ} \mathrm{C}, 200{ }^{\circ} \mathrm{C}\right.$ and $\left.210{ }^{\circ} \mathrm{C}\right)$, kept the set time (1.5 h, $2.5 \mathrm{~h}, 3.5 \mathrm{~h}$, and $4.5 \mathrm{~h}$ ).

(3) Cool stage. After treatment, stopped heating and putting steam into the tank when the temperature was lower than $80{ }^{\circ} \mathrm{C}$. Finally, the samples should be taken out when the tank temperature was equal to the room temperature.

(4) Post-processing stage. Equilibrium moisture content of heat-treated wood was low, and in this paper, the teat-treated samples were kept in the conditioning chamber $\left(20^{\circ} \mathrm{C}, 65 \%\right.$ R.H. $)$ for 15 $\mathrm{d}$ to make the moisture content reach equilibrium.

\subsection{Tests}

(1) Mechanical properties

Modulus of rupture (MOR) and modulus of elasticity (MOE) of poplar wood and modified poplar wood were tested by using the methods specified in GB/T 1936.1-2009 and GB/T 1936.2-2009 standard methods respectively.

(2) Dimensional stability

Anti-shrinkage tests of poplar wood and modified poplar wood were determined by the method specified in GB1934-91. By analyzing the volume shrinkage of poplar wood before and after modification, the anti-shrinkage coefficient (ASE) could be determined. And the value of ASE would be considered as the key indicator for analyzing dimensional stability of modified wood. The equation is expressed as follows:

$$
P_{A S E}=\frac{S_{1}-S_{2}}{S_{1}} \times 100 \%
$$

Where $\mathrm{P}_{A S E}$ is the anti-shrinkage coefficient, $\mathrm{S}_{1}$ is the volume shrinkage ratio of poplar wood, $\mathrm{S}_{2}$ is the volume shrinkage ratio of modified poplar wood.

\section{RESULTS AND ANALYSIS}

\subsection{Influence of different treat conditions on mechanical properties}

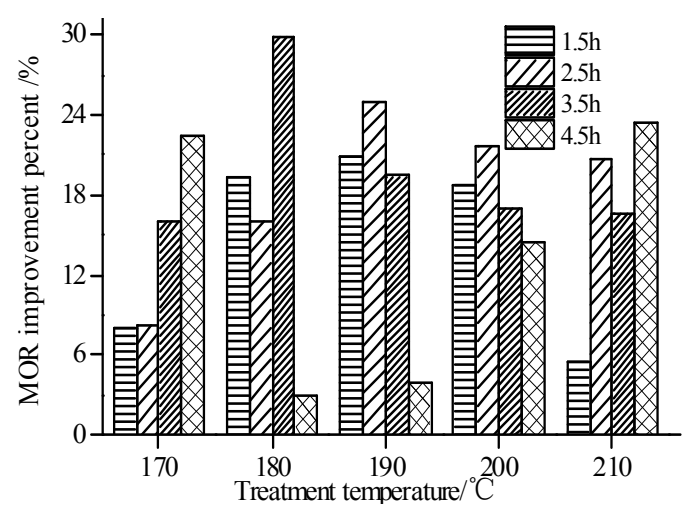

Figure $1 \mathrm{MOR}$ variations of heat-treated wood in different temperature 


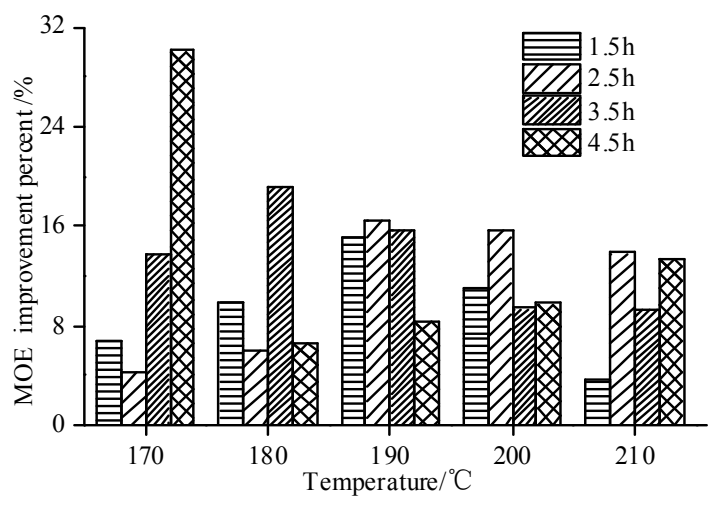

Figure $2 \mathrm{MOE}$ variations of heat-treated wood in different process conditions process conditions

Figure 1 and Figure 2 showed the improvement percentage of MOR and MOE of heat-treated wood samples in the conditions of different processing temperature and time. It could be seen from the figures that no matter how the processing time and temperature changed, the values of MOR and MOE increased to varying degrees. And it could be judged from Figure 1 that the values of MOR were increasing with temperature rising when the processing time were $1.5 \mathrm{~h}, 2.5 \mathrm{~h}$ and $3.5 \mathrm{~h}$.

Moreover, when the processing temperature and time were $180{ }^{\circ} \mathrm{C}$ and $3.5 \mathrm{~h}$, the improvement percentage of MOR of heat-treated samples was the highest in the series of experiments, which was $25 \%$. It was concluded that treat temperature could affect the improvement percentage greatly. Seen from Figure 1 and Figure 2, when the treat time was $4.5 \mathrm{~h}$, the improvement percentage changed dramatically. It could be judged that during the section of treat temperature $\left(180 \sim 200^{\circ} \mathrm{C}\right)$, organic compounds were volatized and the structure of wood was changed by high temperature that influenced the values of MOR and MOE significantly.

However, longer treat time had negative effect on the improvement percentage of MOR and MOE. When the treat time were $3.5 \mathrm{~h}$ and $4.5 \mathrm{~h}$, the percentage of MOR and MOE of heat-treated wood maintained a downward trend. It was only $6.6 \%$ of improvement percentage that when the treat time and temperature were $4.5 \mathrm{~h}$ and $180{ }^{\circ} \mathrm{C}$ respectively. It could be concluded that high temperature would put adverse effect on MOE because high temperature would make fibers in wood crack so as to destroy the stability of wood structure, then the mechanical properties of wood would be weakened[P. Bekhta, 2003].

\subsection{Influence of different treat conditions on physical performance}

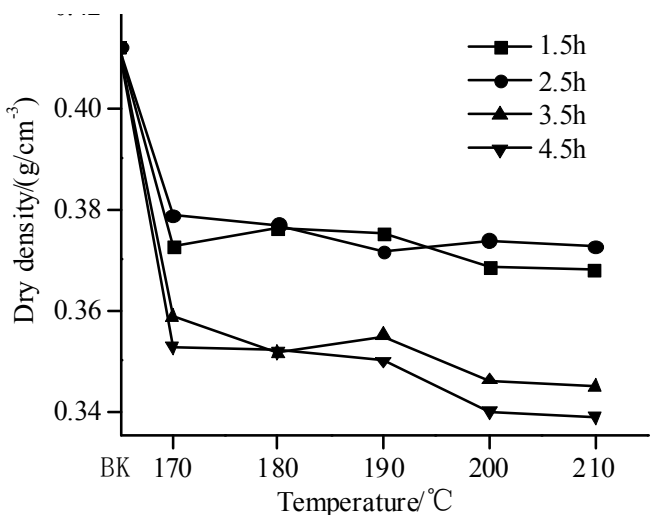

Figure 3 Dry density variations of treated wood 


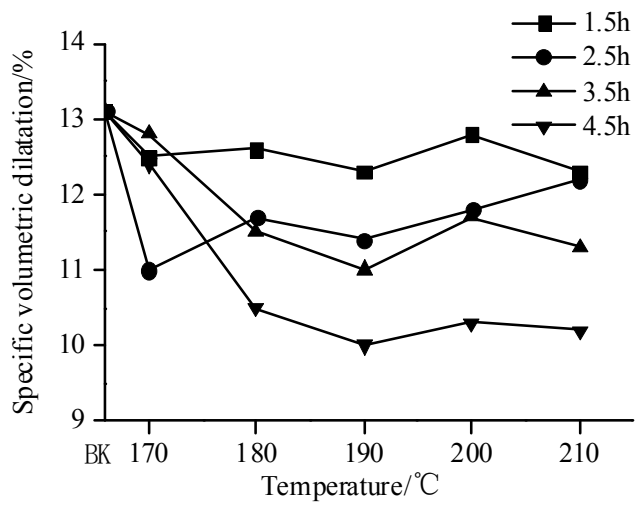

Figure 4 Specific volumetric dilatation variations of heat-treated wood in different process conditions

Heat treatment plays an important role on the change of dry density and specific volumetric dilatation of treated wood. It can be seen from Figure 3 that after treatment the samples suffered weight loss and volume shrinkage, and therefore densities of heat-treated samples were less than blank samples.

Dry density of treated samples was decreasing with treat time and temperature rising. What's more, the longer the treat time was, the smoother the change trend of dry density was. In the same time, the change trend of specific volumetric dilatation was the same as that of dry density [Cao Yongjian, 2011]. It can be judged from the figures above that during treatment, the organic compound in wood was volatized and the main structure of wood samples was stabilized by fiber vitrification in order to make treated samples more stable in series of tests.

\subsection{Influence of different treat conditions on dimensional stability}

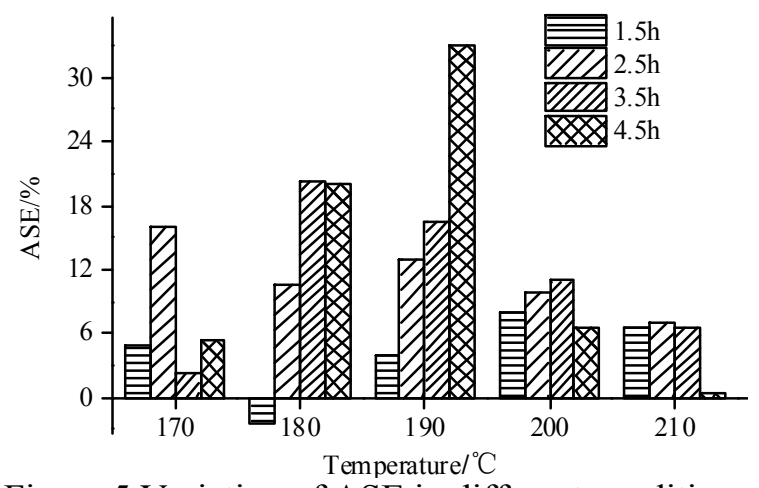

Figure 5 Variation of ASE in different conditions

ASE is a very important factor to investigate physical performance of heat-treated wood. The larger the ASE is, the better dimensional stability of wood samples is. It can be seen from Figure5, in longer treat time $(3.5 \mathrm{~h}$ and $4.5 \mathrm{~h})$, ASE of treat samples was first rising and then falling with temperature continuously increasing. However, when the treat time was $2.5 \mathrm{~h}$, ASE was falling with temperature rising while the treat effect was less than that in the other conditions with $1.5 \mathrm{~h}$ as treat time. When the treat temperature and time were $180{ }^{\circ} \mathrm{C}$ and $1.5 \mathrm{~h}$, the lowest value of ASE was $-2.5 \%$ that mean the dimensional stability of samples was weakened and its physical property was worse than contrast blank samples. The reason may be that too short treat time would make fiber vitrification incomplete and cause the reduction of ASE. When the treat time and temperature were $4.5 \mathrm{~h}$ and $190{ }^{\circ} \mathrm{C}$, the value of ASE was the highest in the series of experiments which was $33.1 \%$.

The reason of the difference between treated samples and the untreated may be that in cellulose amorphous region the hydroxyl groups on the cellulose macromolecular chains and the hydroxyl groups of lignin are partly combined with each other that results in getting rid of 1 molecule of water to form -O- structure. Therefore, the total amount of hydroxyl groups is decreasing significantly and reducing the capacity of water absorption to improve dimensional stability of heat-treated samples[D. P. Kamdem, 2002], [B. Sundqvist, 2006].

Hemicellulose is amorphous substance with hydrophilic groups both in main chains and side chains. After heat treatment, concentration of free hydroxyl is decreasing significantly that reduces 
the capacity of water absorption and internal stress in order to weaken the exchange capacity of water inner and outer wood. Besides, some of the hemicellulose sugars of easily were easily degradable of aldehydes and small molecule carbohydrates. Under the force of high temperature, degradation products would then be polymerized to insoluble polymers and the capacity of water absorption was weakened obviously[B. F. Tjeerdsma , 1998], [G. N. Inari, 2007.].

\section{CONCLUSIONS}

It is effective to improve dimensional stability and physical performance of thermal modification wood samples. MOE and ASE of wood were influenced by temperature significantly but by time limited. MOR was effected by both time and temperature. Then by comprehensive consideration of technological conditions and costs and other factors, the time and temperature of the optimum technological condition were $180^{\circ} \mathrm{C}$ and $3.5 \mathrm{~h}$. Thermal modification technology is of fast processing speed, low cost and good effect, and therefore in the future research properties of heat-treated wood will be studied further in order to provide a solid theoretical foundation for the future industrialization and application of the industry. And in the following study, other mediums will be applied and to improve modification effect and further cut the total cost of thermal modified wood.

\section{ACKNOWLEDGEMENT}

This work is supported by the Science and Technology Project of Forestry Department of Hunan Province, China. *means corresponding author.

\section{REFERENCES}

[1] Chen Zejun et al. 2008. Study on dipping modification technology of fast-growing China fir of Hunan Province. Hunan Forestry Science \& Technology 3:11-13.

[2] B. F. Tjeerdsma et al. 2005. Chemical changes in hydrothermal treated wood: FTIR analysis of combined hydrothermal and dry heat-treated wood. 2005, European Journal of Wood and Wood Products 2:102-111.

[3] R. G. Martinez et al. 1996. Influence of Wood Heat Treatment, Temperature and Maceration Time on Vanillin, Syringaldehyde, and Gallic Acid Contents in Oak Wood and Wine Spirit Mixtures. American Journal of Enology and Viticulture 47:441-446.

[4] J. Ratnasingam. 2011. Effect of heat treatment on the machining and other properties of rubberwood. European Journal of Wood and Wood Products 9:1-3.

[5] Zhang Yamei et al. 2013. Effect of Steam Heating on the Color and Chemical Properties of Neosinocalamus Affinis Bamboo. Journal of Wood Chemistry and Technology 33:235.

[6] B. F. Tjeerdsma et al. 2005. Chemical changes in hydrothermal treated wood: FTIR analysis of combined hydrothermal and dry heat-treated wood, European Journal of Wood and Wood Products 63:102-111

[7] P. Bekhta et al. 2003. Effect of high temperature on the change in color, dimensional stability and mechanical properties of spruce wood. Holzforschung 57:539-546.

[8] Cao Yongjian et al. 2011. Increased dimensional stability of Chinese fir through steam-heat treatment. European Journal of Wood and Wood Products 25:1-4.

[9] D. P. Kamdem et al. 2002. Durability of heat-treated wood. European Journal of Wood and Wood Products 1:1-6.

[10]B. Sundqvist et al. 2006. Determination of formic-acid and acetic acid concentrations formed during hydrothermal treatment of birch wood and its relation to colour, strength and hardness. Wood Science and Technology 40(7):549-561.

[11]B. F. Tjeerdsma et al. 1998. Characterisation of thermally modified wood: molecular reasons for wood performance improvement. European Journal of Wood and Wood Products 3:149-153.

[12]G. N. Inari et al. 2007. Evidence of char formation during wood heat treatment by mild pyrolysis. Polymer Degradation and Stability 6:997-1002. 